You will notice in the illustration I present you that the spreading is easy and graceful, fitting over the enlargements and that the overlapping at points of narrowing is not bungling; and further with a pair of blunt scissors which you may carry in your vest pockets, the parts of segments can be clipped away so as to avoid even this small amount or irregular thickening if desired, and at the same time not interfere with the utility of the splint, and as layer after layer can be sandwiched with the consecutive layers of the bandage we can easily so shift the pieces as to compensate in the one for the deficit of the other, and when after the limb is once so environed we have lightness and strength combined, a perfect retention with a minimum part of cumberous restraint to the injured tissue. There will be also a lack of the feeling of arbitrary force as in the more cumbersome dressing and, as I think you will at once comprehend, a better physiologic reparative condition.

Excuse me, if I here may seem to impose upon your time and patience in suggesting a further thought,

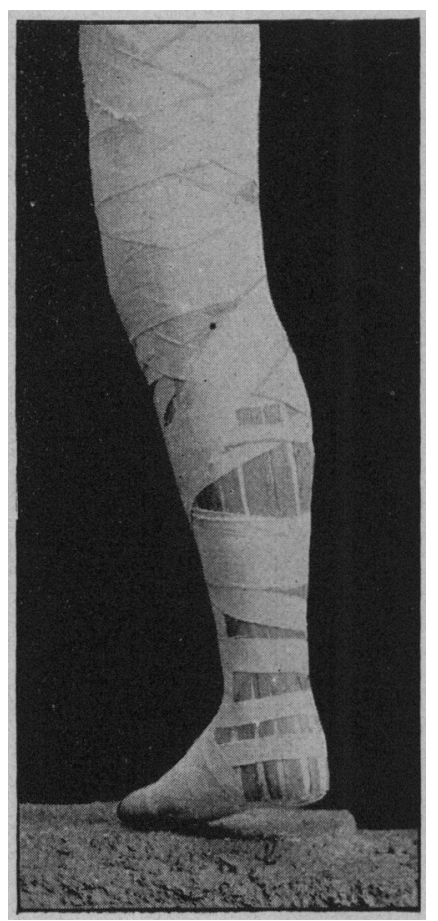

As applied on an artificial limb for demonstration before the session.

that with the interwoven splint and lines of the roller bandage circular, diagonal and longitudinal, up and down the axis of the limb, that the changing of any part of your dressing to the extent of weakening the support or adding to the discomfort of the patient by fulling in cords drawing or pressing from thickening, as is liable to be the case in the cotton under the plaster, or of the plain roller bandage, without stiffening. You will find after weeks of wearing of the shavings that your dressing, bandage and everything else is as smooth and perfect as the hour you first adjusted it.

My experience in observation is that there will be, in no instance, that stiffness of joint or shrinkage in the muscles as is apt to be the case with the more stiff and arbitrary enveloping of the limb, as in plaster or silicate dressings. There will be, at no time, during the time of applying this dressing any danger of losing the proper control of the injured member, as from sudden stiffening nor delay of hardening, as in the use of plaster of paris.

The nature of the stiffening from non-friableness and cohesiveness of the wood and muslin as above, is such that if timely looked to can be changed a little here or there, more or less. You will, I have no doubt, be surprised to learn, in some of these efforts at changing, and appreciate the firmness with which even a small piece or mere splinter, it may be, will remain in its place and thus be assured of the reliability of the method. When you have finished with a few layers completely surrounding the limb, you can lift it with impunity, changing from place to place with the least danger of displacement of the fragment and a minimum of discomfort to your patient. I can only assure you that I have frequently dressed a compound fracture of the leg with loss of substance of tibia and fibula of several inches, with perfect results in the normal line and length. The parts were kept healthy and clean by irrigation or washing for weeks, and until repair was perfect, without changing.

\section{ASEPSIS AND ANTISEPSIS IN OTOLOGY.}

BY J. HOLINGER, M.D.

chICAgo.

The application of the principles of asepsis in all their details has brought great progress in general surgery, in bygiene and in the particular branches of gynecology, obstetrics and ophthalmology; but in some other departments of medicine much is still to be done, before the ideal condition desired by the friends of asepsis will have been attained. Among these latter it seems to me that otology must be included, and that as regards it, the greatest number of scientists underrate the value and misunderstand the necessity for the strictest asepsis. Of course in large operations the instruments are boiled, the patient is cleaned, and as a rule the operator's hands are more or less carefully disinfected. But between this and a complete, consistent and thorough asepsis there is a wide difference. The principles of asepsis should be carried out in otology in the routine examinations of the ear, and especially in the seemingly unimportant details of ambulatory practice. A little reflection will show that hardly anywhere is strict asepsis of more value than in ambulatory practice. Except in cases of very small children we have to use instruments in every examination, and to use them in parts of the body normally covered by only a very tender epidermis, parts that are not accustomed to nor able to endure irritations and that hence are extremely vulnerable. Furthermore, there is no physician who comes so much into contact with putrid and virulently infective material as the otologist. Yet it must be admitted that there are many otologists who do not acknowledge the necessity of asepsis in their department. Their view is not based upon the ab. sence of ill results in their cases, because such results do exist though they are not always readily recognizable and their recognition demands an experienced eye. Even when recognized, there is often lacking in those who are responsible for them the courage to admit them either in public or in private. If a confinement case be managed improperly and uncleanly, the evidences of infection will appear within a few days at the very spot where it occurred 
and a violent form of sickness results. In that case there are hundreds of widely open lymph channels to carry the infection into the blood; but in diseases of the ear the avenue of infection is less apparent and the process is slower, since it takes place through minute openings in the bone. A violence done to any soft part with an infected instrument will show its effects at the very spot within a few days in the form of an acute inflammation, but in otology the place, the time, the manner, the where, when and how of infection are entirely different from what we expect. This is proved by a few examples. Who would expect an erysipelas of the face to originate in a minute injury made by an unclean Eustachian catheter on the mucous membrane far back in the nose? Yet precisely such cases are not infrequent. Again, it would seem hardly possible that a middle ear suppuration of twenty years' standing and ending in necrosis, cholesteatoma, deafness, cerebral abscess and death should have been due to the use twenty years earlier of an unclean ear speculum or probe used by a doctor, or of a hairpin used by a mother in cleaning her baby's ear. Yet such is the origin and history of cases that occur not infrequently in practice. The explanation becomes clear to any one who will follow up the results of bacteriologic examination of aural secretions. It has been established by the independent researches of many investigators that the pus of acute otorrheas contains as a rule only one species of bacilli or cocci and only exceptionally any streptococci; whereas in chronic cases these latter are usually present. In other words, acute infections of the ear are due to a single species of microörganism and heal quickly; while chronic otorrhea is due to a mixed infection with streptococci. Hence the force of the old saying: "As soon as you treat (with non-sterilized instruments) an acute suppuration of the ear, it becomes chronic." No more apt vehicle for mixed infection can be conceived than an ear speculum if it is not properly disinfected, for when used in a sunpurating ear its lumen is certainly soiled by the pus and when applied to the next patient's ear the infectious material is carried inward by the probe and cotton. Thus a chronic otitis is generated which insidiously destroys hearing, and perhaps after the lapse of years even imperils the victim's life. Not less frequent is infection of the soft parts of the external meatus through imperceptible and scarcely avoidable excoriations made by unclean specula. Sometimes the whole meatus is filled with pus, and this a careless examiner may press into and massage into the tissues. The infection will manifest itself either in the form of a general inflammation of the auditory canal or in a local furunculosis. It will not endanger life nor will it last for years, but it causes much pain, and by depriving the patient of sleep and appetite may injure him seriously.

Beside these forms of infection which remain localized, unclean aural instrumentation may be also a means of introducing chronic general poisons, such as those of tuberculosis and syphilis. Many otorrheas are tuberculous, and they may be so without there being any other tuberculous affection present in any part of the patient's body. Cases are recorded of general miliary tuberculosis following a tubercu. lar osteitis of the temporal bone. In the case of syphilis, the sequence can be traced out more directly and more surely. A number of cases have been published of syphilitic primary lesions within the nose and doubtless many more have not been published or have escaped observation. The statement may seem exaggerated, but I believe that it furuishes an explanation for some obscure cases of syphilis without any visible scar of a primary infection on the whole body. Some practitioners may shake their heads and smile at these views and go along in their old dirty ways. So did others when Pasteur and Lister published their principles and results. Time will prove the right. Certain I am that when legislation deals fully with the permissible and the criminal acts of physicians, it will devote a chapter to avoidable infections.

Antiseptic solutions, such as carbolic acid, etc., are generally not thorough enough for disinfection. They Berve rather to lull our consciences. Therefore I would state the following practical rules for aural work :

1. Every instrument should be so constructed that it can be easily cleaned and examined.

2. Before every examination the instruments (speculum, probe, catheter, middle ear instruments) should be sufficiently boiled, and immediately after use they should be washed in cold water, so that the pus, mucus and blood may not coagulate and dry on them. Of course, it goes without saying that the hands must be kept clean according to the general rules of asepsis.

A recent article mentions a handy way of sterilizing the cotton. After being attached to the probe it is dipped into an alcoholic solution of boric acid, and then held in a flame till the alcohol is burned out, the boric acid preserving the cotton from burning.

The carrying out of these principles involves much trouble, time and expense, but they should not be spared in private and especially in dispensary practice, where so many cases, chronic, acute, specific, etc., pass through a rapid examination. The benefit may not be expressed in numbers, but it exists and is worth attaining.

\section{HOW TO SECURE ASEPTIC LABOR. ${ }^{1}$ BY DOWLING BENJAMIN, M.D. CAMDEN, N.J.}

It was a bright day for women when the leaders of scientific investigation in the medical profession announced this discovery that the infectious fevers were caused by minute organisms, called germs or pathogenic bacilli; for it was only by the discovery of the cause of child-bed fever that we were enabled to prevent its occurrence.

To show the importance of this subject I may simply quote you a few figures. Taking New York alone, from 1886 to 1887 there were 3,342 deaths incident to child-bearing. Of these deaths 1,947 were due to child-bed fever, or the infection to the lying-in period. (See Pepper's System of Medicine, vol. 1.)

Fully half of the deaths, therefore, that occur at the confinement period are due to infection, septicemia, pyemia and from blood poisoning. caused by fever germs getting into the system through the abrasions caused by parturition. And you must also remember that aside from any other lesion, there is always after every confinement a large, raw surface left on the interior of the womb by the separation of the afterbirth, which is one of the most dangerous fields for the growth of diseased germs and their ready entrance in to the woman's system.

I Extract from a lecture by Dr. D. Benjamin, Obstetrician at Cooper
Hospital. 